\title{
Low-cost solid catalyst derived from waste Cyrtopleura costata (Angel Wing Shell) for biodiesel production using microalgae oil
}

\begin{abstract}
In the present work, Cyrtopleura costata (Angel Wing Shell) is used for the first time to synthesis of $\mathrm{CaO}$. The produced $\mathrm{CaO}$ was utilized as a catalyst for biodiesel production from microalgae Nannochloropsis oculata oil. The Angel Wing Shell (AWS) was calcined at $800{ }^{\circ} \mathrm{C}$ and $900{ }^{\circ} \mathrm{C}$ for $2 \mathrm{~h}$ to convert $\mathrm{CaCO} 3$ to activate metal oxide phase. The synthesized catalysts were characterized by using Thermogravimetric analysis (TGA), X-ray diffraction (XRD), Temperature programmed desorption of $\mathrm{CO} 2$ (CO2-TPD), BET surface area and Scanning electron microscopy (SEM) analysis. The calcined Angel Wing Shell at $900{ }^{\circ} \mathrm{C}$ (CAWS 900) was chosen as the best catalyst due to its high basicity and surface area. This also corresponded to optimization condition where, CAWS 900 showed highest FAME yield (84.11\%) at oil to methanol molar ratio 1:150 and catalyst loading of $9 \mathrm{wt} . \%$ in $1 \mathrm{~h}$ reaction time. The CAWS 900 catalyst also can be reused more than three times with FAME yield greater than $65 \%$. Overall, AWS appears to be an acceptable solid catalyst to convert microalgae oil to biodiesel.
\end{abstract}

Keyword: Calcium oxide; Waste shell; Microalgae; Biodiesel; Transesterification 